\section{Efectividad de una pasta tri-antibiótica en pieza decidua necrótica con absceso periapical y fístula}

\author{
Effectiveness of Antibiotic paste in necrosed primary teeth with \\ periapical abscess and fistula
}

\section{Resumen}

El objetivo de este trabajo fue evaluar la efectividad de una pasta tri-antibiótica como tratamiento en una pieza con absceso periapical y fístula mediante su acción bactericida en un paciente de cuatro años de edad, con el fin de inhibir los microorganimos presentes y preservar la pieza. Se realizó pulpectomía y se obturó definitivamente cn la pasta tribiótica de ciprofloxacina, metrodinosol y minociclina con vehículo líquido de propilenglicol. Para la preparación de la pasta se removió la cubierta entérica, éstos antibióticos fueron pulverizados en un mortero estéril y luego mezclados con el propilenglicol inmediatamente antes de ser usados. El resultado de esta pasta fue efectiva mostrando mejorías tanto clínica como radiográficamente.

Palabras clave: pasta antibiótica, pulpectomía, diente deciduo necrótico.

\section{Mg. C.D. Carmen Inocencia Quintana del Solar ${ }^{1}$ Magaly Quispe La Rosa}

\author{
1 Departamento Académico de Estomatología \\ Pediátrica. \\ 2 Práctica privada
}

Correspondencia:

Mg. C.D. Carmen Inocencia Quintana del Solar Facultad Odontología, UNMSM

Teléfono: 619700 anexo 3406

e-mail: cquintanad@unmsm.edu.pe

\begin{abstract}
:
The aim of this study was to evaluate the effectiveness of one paste triantibiotica as a treatment in one piece with periapical abcess and fistula. We report a patient of for years old, who had presented a necrotic primary molar with abcess and fistula, we decided to make the pulpectomy using antibiotic paste formed by ciprofloxacin, metronidazole, minocycline and propyleneglycol to inhibit microorganisms present and preserve the piece. After removal of enteric coating, these drugs were pulverized using sterile mortar and pestle, and then one increment of each powdered drug was mixed with propylene glycol to form an ointment just before use. The result of this paste was effective showing clinical and radiographic improvements.
\end{abstract}

Key words: antibiotic paste, pulpectomy, necrotic primary teeth.
Fecha de recepción: 12-09-12

Fecha de aceptación: 23-11-12

\section{Introducción}

Los dientes deciduos necróticos con reabsorción radicular o pérdida ósea en la zona de furca tienen un pronóstico desfavorable y están contraindicados para terapia pulpar. En nińos pequeños la exodoncia prematura no está recomendada debido a la pérdida en la longitud de arco, por la migración mesial de la molar permanente y la consecuente pérdida de espacio. Aún la colocación de mantenedores de espacio, tiene desventajas en términos de función e higiene oral. La preservación de los dientes deciduos constituye el mejor mantenedor de espacio, si es que se puede lograr la resolución de los procesos patológicos asociados a la necrosis pulpar. ${ }^{1}$

En los últimos años, la Unidad de Investigación de Cariología de la Facultad de Odontología de la Universidad de
Niigata ha desarrrollado el concepto de "Lesion Sterilization and Tissue Repair" o "Terapia LSRT" (Hoshino 1990, Iwaku y col 1996, Hoshino y Takushige 1998) que utilizan una mezcla de antibióticos para la desinfección de las lesiones pulpares y periapicales. Los estudios de estos autores incluyeron un gran número de especies bacterianas, que fueron sensibles a una combinación de tres antibióticos: ciprofloxacina, metronidazol y minociclina. La hipótesis de la "Terapia LSRT" propone que la remoción o desinfección de bacterias presentes en estas lesiones se produce por la aplicación local de una combinación de antibacterianos y esto conduce a la resolución de las lesiones periapicales. Además, sus estudios concluyen que cuando se usa la combinación 3Mix (ciprofloxacina, metronidazol y minociclina) con macrogol $(\mathrm{M})$ y propilenglicol
(P), se penetra eficientemente por los túbulos dentinarios, sugiriendo que las bacterias de las lesiones pulpares y periapicales pueden ser alcanzadas por la colocación de la pasta $3 \mathrm{Mix}$ - MP en el piso de la cámara pulpar. Adicionalmente una predicción importante de la "Terapia LSRT" es que la acción local de la efectividad antibiótica en un vehículo apropiado como el propilenglicol puede conseguir la recuperación de los tejidos dańados sin la necesidad de una pulpectomía convencional. ${ }^{2,3,4}$

En una infección endodóntica, la mayor parte de las bacterias son anaerobios estrictos, aunque también podemos encontrar un buen número de bacterias anaerobias facultativas y bacterias microaerófilas. $^{5}$

La mayor parte de casos con necrosis pulpar obedecen a infecciones poli- 
microbianas que incluyen aerobios estrictos y anaerobios facultativos, éstas disminuyen la tensión de oxígeno proporcionando así condiciones favorables para que se desarrollen la bacterias estrictamente anaerobias. ${ }^{5}$

La microbiota de los conductos radiculares con necrosis pulpar y enfermedad periapical está dominada por anaerobios estrictos pertenecientes a los géneros: Fusobacterium, Porphyromonas, Prevotella, Eubacterium y Peptostreptococcus. ${ }^{6}$

Entre los distintos materiales de obturación de uso común en tratamientos pulpares de piezas temporales están: Oxido de zinc y eugenol; pasta Guedes Pinto, conformada por yodoformo, paramonoclorofenol y rifocort; pasta Hidróxido de calcio, como el Vitapex, yodoformo e hidróxido de calcio; pasta tri antibiótica o $3 \mathrm{mix}$, compuesta por la ciprofloxacina, metronidazol y minociclina; y la pasta CTZ, formada por el clorafenicol, tetraciclina y óxido de zinc y eugenol. ${ }^{7,8,9}$

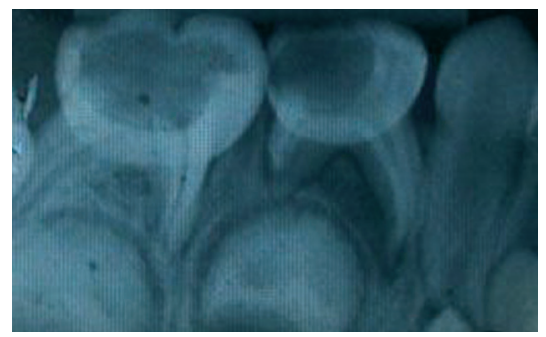

Fig 1. Pieza 8.4 con ensanchamiento del ligamento periodontal e imagen radiolúcida en la zona periapical compatible con absceso.

La pasta tri-antibiótica o 3Mix-MP está indicada en piezas deciduas con necrosis pulpar y es utilizada como una técnica alternativa a la pulpectomía convencional con OZE. ${ }^{9,10,11}$

Esta pasta tiene la capacidad de difundirse a través de los conductos radicu- lares hasta la zona periapical ejerciendo una acción in situ.

La pasta tri antibiótica resulta de la combinación de la parte polvo, conformada por:

- Ciprofloxacina, tiene un efecto bactericida que actúa en infecciones periapicales.

- Metronidazol, efecto bactericida indicado en infecciones anaerobias.

- Minociclina, actúa contra bacterias anaerobias y aerobias.

La parte líquida está formada por el propilenglicol, que actúa como vehículo eficaz, pues tiene la capacidad de penetrar rápidamente la dentina y actuar contra la lesión. ${ }^{5}$

\section{Caso clínico}

Paciente de sexo masculino de 4 años de edad que acude a la consulta refiriendo un dolor intenso y localizado; clínicamente se observa una lesión cariosa profunda en la pieza 8.4 , además de una fístula en vestibular. (Fig. 2)

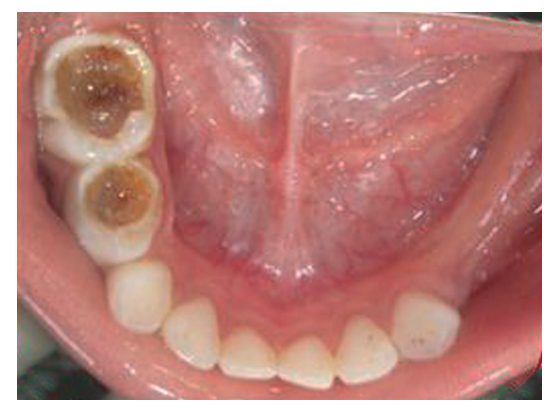

Fig 2. Imagen clínica de la pieza afectada.

Radiográficamente se observa una imagen radiolúcida en oclusal que compromete esmalte y dentina con aparente compromiso pulpar, y una imagen ra- diólucida que rodea la zona periapical. (Fig. 1)

\section{Diagnóstico}

Del estado de salud general: Paciente en aparente buen estado de salud general, con antecedente de anemia. Del estado de salud estomatológico: Necrosis pulpar y absceso periapical en la pieza 8.4 . Tipo de paciente: Colaborador.

\section{Plan de tratamiento}

Se decide realizar la pulpectomía en la pieza 8.4 , donde la pasta tri antibiótica o 3 mix será el material de obturación definitivo.

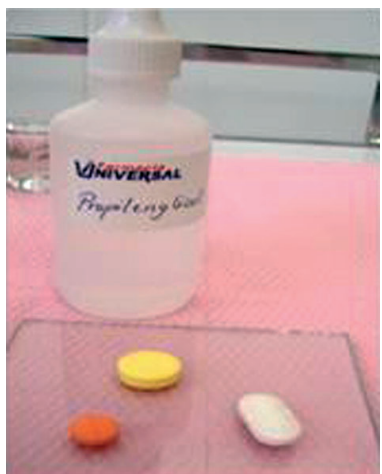

Fig 3. Presentación de los medicamentos.

Para la preparación de la pasta tri antibiótica se consiguió cada una de las pastillas en su forma comercial (Fig. 3), utilizando tres recipientes estériles y secos se pulverizó cada una de las pastillas (ciprofloxacina, metronidazol y minociclina) por separado, y luego se combinó con el componente líquido viscoso (propilenglicol) que actúa como vehículo difusor en los túbulos dentinarios. (Fig. 4).
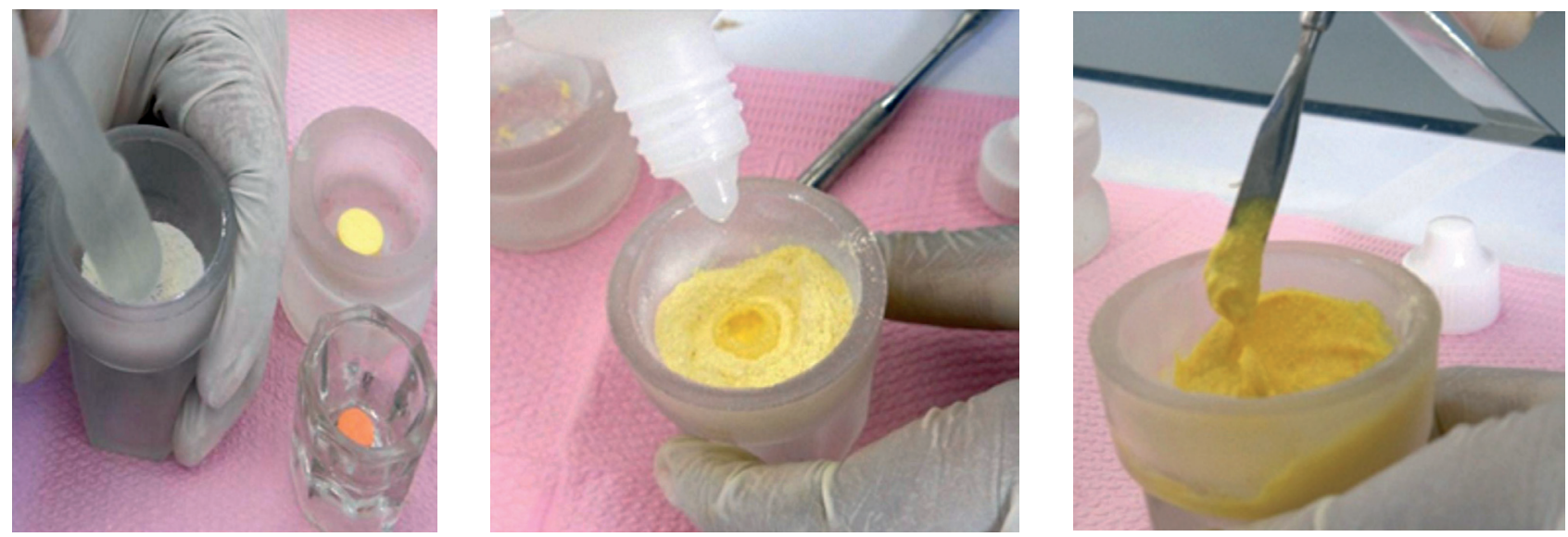

Fig 4. Preparación de la pasta tri antibiótica. 


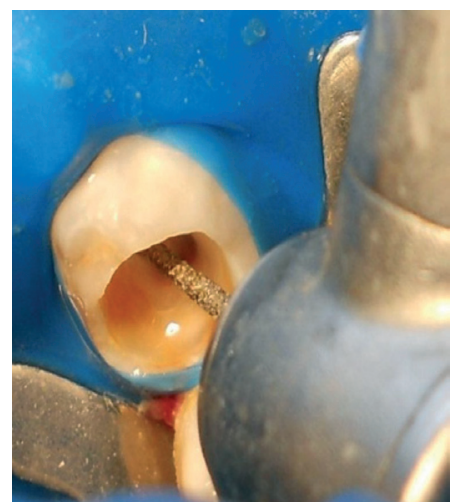

Fig 5. Remoción del tejido cariado

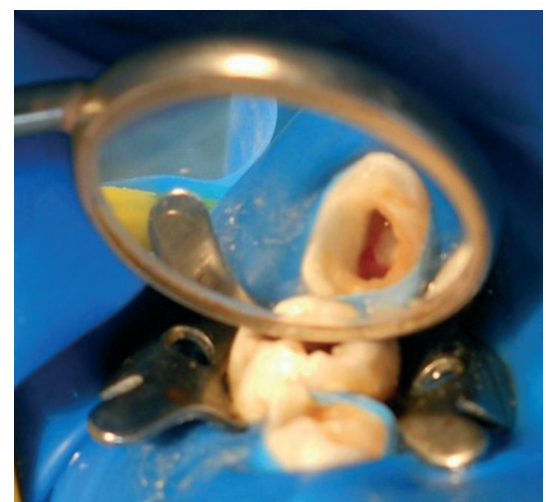

Fig 6. Apertura cameral

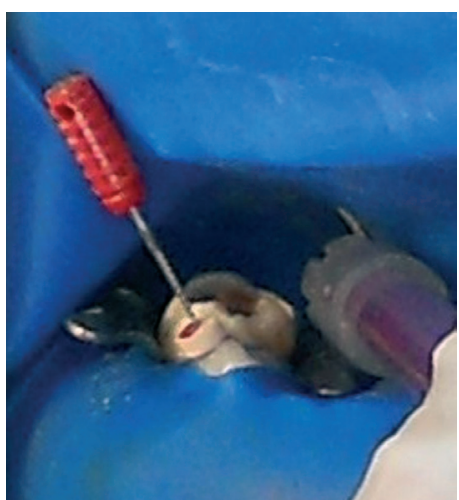

Fig 7. Eliminación del tejido pulpar

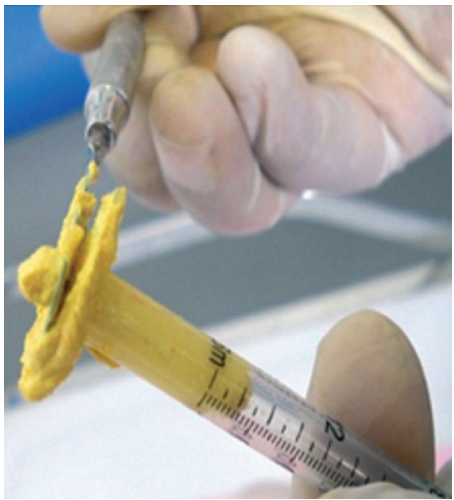

Fig 8. Llenado de jeringa con la pasta.

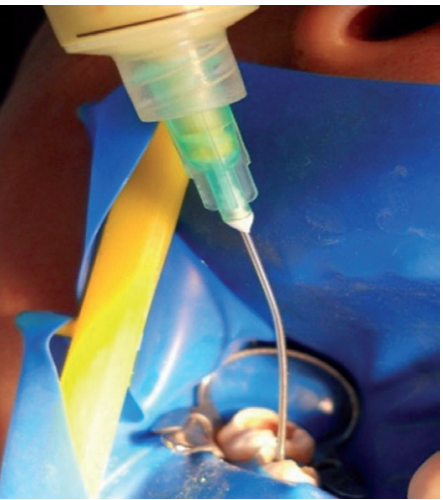

Fig 9. Obturación con la pasta tri antibiótica.
Para el procedimiento clínico se procedió a la aplicación de la anestesia troncular previo al aislamiento absoluto del campo operatorio. Luego se realizó la remoción del tejido cariado con fresas de alta velocidad y curetas de dentina estériles, (Fig. 5). El siguiente paso fue la apertura cameral y la eliminación del tejido pulpar tanto cameral como radicular mediante el uso de limas K-file (Fig. 6). Por el grado de infección endodóntica se realizó la irrigación con una parte de Hisol (hipoclorito de sodio) diluido en 3 partes de agua.

Con el campo operatorio seco, se procedió a colocar la pasta tri antibiótica en la entrada de los conductos mediante el uso de una jeringa hipodérmica (Fig. 8), la literatura menciona que también tulos. Finalmente, se obturó con pasta ZOE a nivel cameral hasta oclusal de forma temporal.

\section{Resultados}

Se tomó una radiografía de control el mismo día del tratamiento, observándose que la pasta tri antibiótica se presenta como una imagen radiolúcida. Clínicamente se observó que la fístula 10). A los 15 días, se vuelve a tomar una nueva radiografía de control, observanse pueden usar las limas K- file o los lénempezó a drenar y el dolor cesó. (Fig. do una leve radiopacidad de la lesión y la ausencia completa de la fístula y del dolor.

Se hace un seguimiento clínico y radiográfico a los 6 meses, se observa una mayor radiopacidad, lo que indica la reparación de la zona periapical y ausencia de molestia alguna. Viendo el progreso en la mejoría de la lesión, se puede tomar como opción la reconstrucción de la pieza
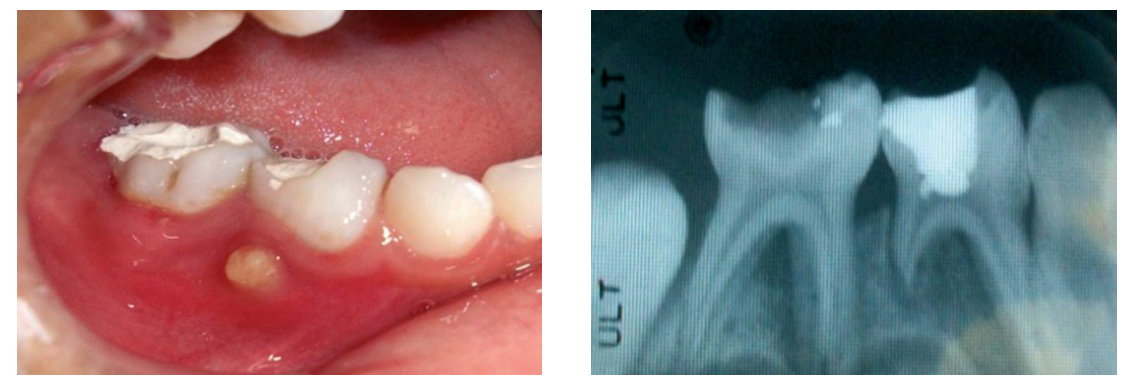

Fig 10. Control clínico y radiográfico el día de la obturación.
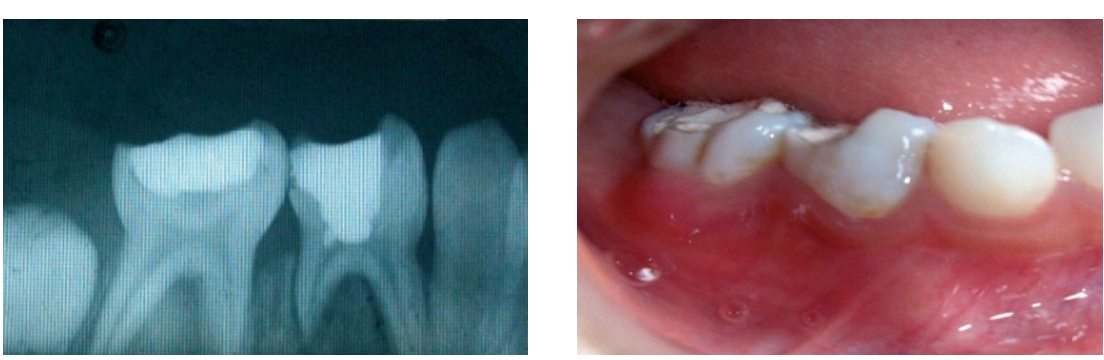

Fig 11. Control radiográfico y clínico a los 15 días.

decidua e instalación de una corona metálica preformada.

\section{Discusión}

Sato y col., mezclaron los medicamentos (ciprofloxacina, metronidazol y minociclina), y demostraron la inhibición del crecimiento de bacterias en muestras de lesiones cariosas y endodónticas que ellos realizaron en placas, a lo que
Odontol. Sanmarquina 2012; 15(2):31-34 

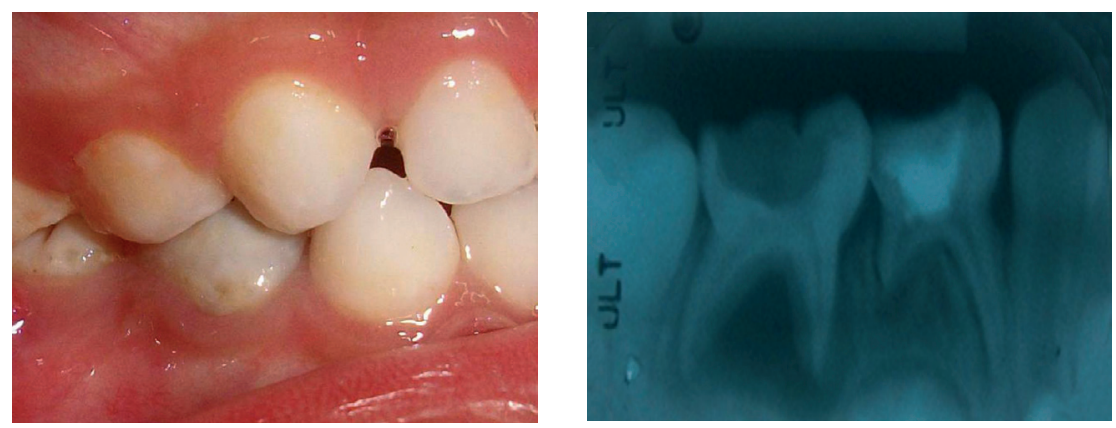

Fig 12. Control clínico y radiográfico a los 6 meses.

la bacteria no se recuperó en ninguna de las lesiones. ${ }^{4} \mathrm{Al}$ igual que en este caso, se demuestra la inhibición de los microorganismos presentes en lesiones periapicales.

Hoshino y col, colocaron la pasta 3 Mix - MP en el piso pulpar de una lesión cariosa, evidenciando el reblandecimiento y recalcificación de la dentina. ${ }^{1}$ Como se mencionó anteriormente, una de las características principales del propilenglicol en esta pasta es la difusión rápida a través de la dentina a la zona de la lesión.

Según Tamanna y col., la pasta tri antibiótica (3 mix - MP) es suficientemente capaz de inhibir el crecimiento de enterococos, y ser útil para el tratamiento de endodoncia. ${ }^{2}$ En este caso se demostró la efectividad de la pasta tri antibiótica ante una infección bacteriana aplicada a la pulpectomía.

Takushige y col., demostraron en un estudio que la recuperación de bacterias disminuye con el tiempo después de la aplicación de la combinación de drogas. ${ }^{4}$ Esto se hizo notorio en el caso presentado, por las mejorías tanto clínicas como radiográficas después de haber realizado el tratamiento.

\section{Conclusiones}

La pasta tri antibiótica (3 Mix- MP) presentó un resultado eficaz en el tra- tamiento de la pieza decidua por su acción directa en los conductos.

El diagnóstico pulpar debe ser realizado cuidadosamente, ya que esta pasta actúa ante determinadas bacterias y está técnica de pulpectomía basada en la Terapia LSRT, se debe reservar para casos específicos, como demuestra la evidencia científica.

Al realizar el tratamiento con la pasta tri antibiótica (3 Mix - MP) se observó mejorías tanto clínicas como radiográficas lo que indica su efectividad en el tratamiento.

\section{Referencias Bibliogáficas}

1. Hoshino E., Takushige T, Venzon E., Asgor A. Non-surgical treatment of pulpitis, including those with history of spontaneous pain, using a combination of antibacterial drugs. Journal of LSTR Therapy (International WEB version) 2008:7: 1-5.

2. Sato I, Ando-Kurihara N, Kota K, Iwaku M, Hoshino E. Sterilization of infected root-canal dentine by topical application of a mixture of ciprofloxacin, metronidazole and minocycline in situ. International Endodontic Journal 1996 Mar;29(2):118-24

3. Takushige T, Cruz E, Moral A, Hoshino E. Endodontic treatment of primary teeth using a combination of antibacterial drugs. International Endodontic Journal, 2004;37:132138.

4. Quispe A. Evaluación del efecto antibacteriano de la combinación de drogas 3 mix en bacterias anaerobias prevalentes en necrosis pulpar. [tesis para el título de Cirujano dentista]: Lima: Universidad Nacional Mayor de San Marcos; 2007. Disponible en: http://www.cybertesis. edu.pe/sisbib/2007/quispe_sa/pdf/ quispe_sa.pdf

5. De Rezende L, Lopes N. Viabalidade da utilizacao da Pasta GuedesPinto na Pulpotomia em Dentes Deciduos: Revista da Literatura. Revista Odontologia do Brasil Central. 1992;2(4):8-12

6. Nakornchai S, Banditsing P, Visetratana N. Clinical evaluation of 3Mix and Vitapex as treatment options for pulpally involved primary molars. Int Journal of Paediatric Dentistry. 2010;20:214-221

7. Agarwal M, Mohan U, Vishwanath D. A comparative evaluation of noninstrumentation endodontic techniques with conventional $\mathrm{ZOE}$ pulpectomy in deciduos molars: An in vivo study. World Journal of Dentistry, 2011; 2(3):187-192

8. Kargül B, Tanboga I, Altinok B. Conventional endodontic treatment of primary molars using metronidazol as an intra-canal medicamente: a pilot study. European Archives of Paediatric Dentistry 2010;11(4):196-200

9. Pinky C, Shashibhushan KK, Subbareddy VV. Endodontic treatment of necrosed primary teeth using two different combinations of antibacterial drugs: An in vivo study. Journal of Indian Society of Pedodontics and Preventive Dentistry. 2011;29(2):121-127 